\title{
Coastal Wave Measurements by Exploitation of Jason-2 PISTACH in the Vicinity of Visakhapatnam Region on East Coast of India
}

\section{Acharyulu PSN ${ }^{1 *}$, Prasad KVSR ${ }^{1}$, Vignudelli Stefano ${ }^{2}$, Rashmi Sharma ${ }^{3}$ and Venkata Ramu $\mathrm{Ch}^{1}$}

${ }^{1}$ Department of Meteorology and Oceanography, Andhra University, Visakhapatnam, Andhra Pradesh, India

${ }^{2}$ Consiglio Nazionale delle Ricerche, Istituto di Biofisica, Pisa, Italy

${ }^{3}$ Space Applications Centre, Atmospheric and Oceanic Sciences Group, Ahmedabad, Gujarat, India

*Corresponding Author: Acharyulu PSN, Department of Meteorology and Oceanography, Andhra University, Visakhapatnam, Andhra Pradesh, India.
Received: August 28, 2020

Published: October 22, 2020

(C) All rights are reserved by Acharyulu

PSN., et al.

\section{Abstract}

Satellite altimetry provides precise measurements of wind speed and significant wave height. They have been validated and widely used over open ocean, however, when they come closer to the coast, there is still a need to assess their accuracy and potential usage. This is especially true along Indian coasts, which experience quite opposite northeast and southwest monsoons and a calm period in between them. In this paper, Study on coastal wave heights using JASON-2 tracks in and around Visakhapatnam was carried out, on the east coast of India where the in situ measurements are available to us. Of the new additional three re-trackers available with the PISTACH coastal products, the results show that the RED3 re-tracker performs well with the coastal buoy. The coastal buoy as well as the altimeter capture all the oceanographic signals. The results from comparisons suggest that there is a significant improvement in the significant wave height (SWH) altimeter observations in terms of noise and accuracy after processing. In particular, it was observed that RED3 re-tracker shows better matching with the moderate wave height ranges and better results in proximity of the coast where as OCE3 re-tracker captures all the signals especially during severe weather conditions with less error and better results at intermediate and open waters. The wave height measurements obtained from Jason-2 PISTACH products in the coastal regions are substantially in good agreement with the coastal buoy measurement. There is a need to improve better detection of outliers, which were present even after processing. Also, there is a need to enhance or modify the collocation criteria for coastal regions otherwise the wave which was observed by the altimeter and the buoy will not be the same. These results shows that the Jason- 2 PISTACH data able to extend the altimeter data up to $\sim 10 \mathrm{~km}$ proximity to the coast and the potential use of RED3 re-tracker in the coastal zone and the use of both the re-trackers in understanding the wave climate in the coastal zone on the east coast of India especially where in-situ observations were scarce. This data will be useful to study the spatial variability and better understanding of coastal dynamics in these limited areas. The results were quite encouraging to use the altimetry data in the coastal regions on the east coast of India. Keywords: Satellite Altimetry; Coastal Zone; Coastal Processes; Significant Wave Height; Seasons; Low Pressure Systems

\section{Introduction}

Wind wave information is useful for many off shore and marine activities, navigation, oil exploration, etc. Ocean wave information is obtained through in-situ measurements, modeling and remote sensing. Each technique has its own limitations. Obtaining wave information in remote and data sparse regions like on the east coast 
of India is possible through remote sensing. Radar altimeter is an important tool to observe sea surface height, ocean surface waves and wind speed. The potential benefits of the satellite altimeter wave height data include ship routing, fisheries, coastal protection, oil exploration and in modeling studies to specify initial sea state condition and for validation of wave forecast [1]. The satellite radar altimeter can be able to provide precise, less-noise measurements of the significant wave height of ocean waves by analyzing the shape of the return pulse [2]. The altimeter serves as a best alternative in terms of both temporal and spatial scales to expand this study for the measurement of short period waves [3]. There are two methods of comparison and validation of altimeter data, one making global statistical analysis and another doing cross validation at same time and location [4]. Many studies on calibration and validation of altimeter data both temporal and spatial scales [4-11] made significant progress in improving the quality. P Queffeulou [9] reported that the wave data observed from altimeter was found to be consistent with the measured buoy data, but the space-borne observations are found to be less correlated for severe sea states [8]. Although there is an availability of altimeter data close to the coast, data were often discarded due to difficulty in processing and interpretation. But, a meaningful measurements were recovered from the altimeter in the coastal zone of $0-50 \mathrm{~km}$ by reprocessing the radar echoes and by applying enhanced corrections [12].

Satellite altimetry study over open ocean is well established and now one of the difficult task lies in extending its application to near-coastal regions, although the purpose of the sampling strategy was not intended for the coastal study [13]. In the last few years, several efforts have been made to enhance the quality of the altimetry data close to the coasts and significant progress was achieved by developing new retracking algorithms within the framework of coastal dedicated projects like COASTALT [14], PISTACH [15], e-Surge (ALES [16]), PEACHI [17] etc. by reprocessing altimeter data in the limited areas of coasts [18] and by organizing a series of COASTALT workshops.

A Sarkar., et al. [19] carried out an inter comparison of altimeter derived and model predicted wave heights over the North Indian ocean and achieved moderate matching results. ED Kumar., et al. [8] studied the wind-wave characteristics and climate variability in the Indian ocean by categorizing into 6 zones. L Sabique., et al. [20] made a quantitative comparison of collocated grid averaged altimeter and buoy data and observed an underestimation of al- timeter data by $0.2 \mathrm{~m}$. Recently, PR Shanas., et al. [21] carried out a comparison study over the same study region along with other locations with $100 \mathrm{~km}$ and 30 min collocation criteria using gridded multi mission and along track mono mission data for the year 2010. But, still this limits the use of altimetry as far as $100 \mathrm{~km}$ away from the coast in the Indian coastal regions. The satellite altimeter provides precise measurements of wind speed and significant wave height. They have been validated and widely used over open ocean, however, when they come closer to the coast there is still a need to assess their accuracy and potential usage. This is especially true along Indian coasts, which experience quite opposite northeast and southwest monsoons and a calm period in between them. In this paper, an attempt made to identify the best re-tracker available in theJason-2 PISTACH product for observing coastal wave heights on east coast of India. To check the data validity closer to the coast and to which extent reliable altimeter wave measurements could be exploited as close as possible to the coast. This study is important for obtaining wave parameters in proximity of coastal areas, which are useful to study coastal dynamics and to understand several near shore processes [22].

\section{Methods}

In this section, the strategic location of the study area was discussed in detailed. The details of the in-situ measurements and Satellite Altimeter data was discussed. Also the altimeter data processing and collocation criteria were discussed.

\section{Study area}

The Study area is strategic location off Visakhapatnam on the east coast of India abutting the Bay of Bengal, between $17^{\circ} 38^{\prime} 30^{\prime \prime}$ to $17^{\circ} 47^{\prime} 10^{\prime \prime} \mathrm{N}$ and $83^{\circ} 7^{\prime} 30^{\prime \prime}$ to $83^{\circ} 7^{\prime} 30^{\prime \prime} \mathrm{E}$ with an area of about $270 \mathrm{~km}^{2}$ as shown in figure 1 .

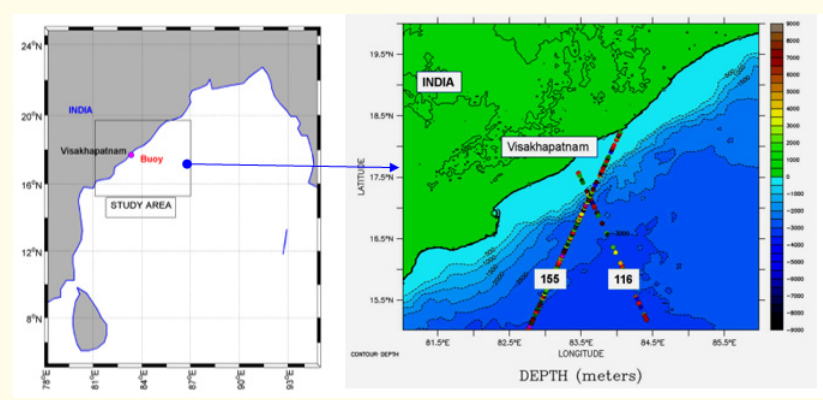

Figure 1: Study region with buoy location and Jason-2 passes. 
This port city is a complicated costal stretch characterized by rocky headlands, promontories, pocket beaches, port structures, breakwaters etc. The coast is occupied with two major ports - the Visakhapatnam port and the Gangavaram port [23]. The reason for the selection of the location is the availability of a closest altimeter track to the in-situ buoy in comparison with other buoys located in east coast of India. Being in the tropics, the climate of this region is governed by the monsoons. A year depending upon monsoon conditions divided into four seasons namely:

- The North-East monsoon which lasts from end of November to end of February with primarily winds blowing from North East and cyclones that are frequent during November.

- $\quad$ The pre-monsoon period extend from March to May which lasts with the commencement of the hottest period of the year, during which the winds started to shift towards SouthWest in direction and cyclones that are frequent in the month of May.

- The South-West monsoon period falls from June to September, where the winds blow from South-Westerly direction associated with cloudy weather and frequent rains.

- $\quad$ The post-monsoon period usually starts from mid of October and lasts up to the November with variable weather and associated with fierce cyclones with relatively greater frequency.

\section{In-situ data}

The In-situ wave data was obtained from Indian National Center for Ocean Information Services (INCOIS) (www.incois.gov. in) through FTP service. Wave data is routinely measured in the study region by INCOIS operated by the National Institute of Ocean Technology (NIOT). Data are available as quality controlled half an hourly of Significant wave height, Wave direction and Wave period the reference being a benchmark connected to the national datum. The wave rider buoy was installed at $1.3 \mathrm{~km}$ ( $\sim 20 \mathrm{~m}$ depth) off Visakhapatnam on the east coast of India. The study period was from January-2010 to September 2013 of about 3 years and 9 months in duration. The location of the buoy indicates that it is coastally located about 18 and 50 kilometers away from the altimeter tracks 116 and 155 respectively but still an attempt made to compare and validate altimeter data with buoy and to check the validity of altimeter data close to the coast obtain reliable estimates of wave heights in the coastal regions.

\section{Altimeter data}

Satellite Altimeter along track data are obtained from the AVISO (Archiving, Validating and Interpretation of satellite oceanographic data) website (www.aviso.oceanobs.com) through ftp service. In order to develop satellite radar altimeter products over coastal areas and continental waters in the Jason-2 Project, Centre National d'Etudes Spatiales (CNES) funded the PISTACH (Prototype Innovant de System de Traitement pour les Applications Cotieres et 1 Hydrologie) project to CLS. It consists of two products namely Coastal, covering the whole ocean plus a $25-\mathrm{km}$ fringe over land and Hydrology, with all emerged lands plus a $25-\mathrm{km}$ fringe over oceans [15].

During the experimental PISTACH project, PISTACH is provided with three additional re-trackers RED3, OCE3and ICE3 in addition to standard MLE4 retracker. But for coastal studies, only RED3 (MLE3 retracking on reduced waveform to reduce the land contamination) and OCE3 (MLE4 retracking applied on filtered waveform) [24] in addition with standard product are available. The PISTACH products include new retracking solutions, several state-of-the-art geophysical corrections as well as higher resolution global/local models, in addition to the content of standard Jason-2 IGDRs with high resolution along track products $(20 \mathrm{~Hz}$ sampling rate, with fields either interpolated or copied) and about 80 extra fields [15]. Each algorithm has its own retracking strategy and so their outputs are different for each re-tracker.

The data selected for the study were the Interim Geophysical Date records (IGDR) of the Jason-2 PISTACH coastal products. The Jason-2 ground tracks (or passes) selected for the study region are track number 155 and 116 with 10 day repeat cycle. The study period covers Jason-2 repeat cycles from 55 to 192.

\section{Altimeter data processing}

The processing of altimeter data consists of data editing and filtering [24]. Data editing includes data flagging and data restriction. In data flagging, land flag and the respective PISTACH processing flag for re-trackers [15] was applied to obtain valid data. This study was started where the standard altimeter data was left off to the coast. This zone can be selected by restricting data between 16-18 degree latitude and by applying shoreline distance flag between 10(0)-50 km for the track 155 (track 116). Significant wave height $(\mathrm{SWH})$ data was only considered within the range of 0-11 m otherwise rejected. Here, rain flag data was not applied 
in order to obtain more number of collocated points. Finally, a Lanczos (low pass) filter was applied at different spatial scales to reduce the high frequency noise.

\section{Collocation criteria}

The sampling and coverage properties of satellite wave measurements and buoy are quite different [3], one is spatial and another one is temporal. So, the comparison between the satellite and in situ observations may differ even if both instruments collect accurate estimates [25]. But it is necessary to compare and validate satellite measurements with traditional and well proven in situ measurements. A common criteria adopted for the comparison of satellite altimeter data is collocation criteria. This criteria defines the reliability of wave measurements in both space and time scales. The general collocation criteria ranges from 0 - $1.5 \mathrm{hrs}$ and $0-150 \mathrm{~km}$, but widely used ranges are $0-0.5$ and $0-50 \mathrm{~km}$ in temporal and spatial scales respectively. For the similar study region, [21] used $0-0.5 \mathrm{hr}$ in temporal and spatial window has extended to $100 \mathrm{~km}$ to obtain more collocation points. In this present study, the collocation of altimeter data is from open ocean to coastal buoy data. So, this collocation criteria as small as possible otherwise the wave which was observed by the altimeter and the buoy will not be the same. For this, the equatorial passing time plus eight min (time taken for altimeter track to pass from equator to land over the study region) gives the exact time of the altimeter passing over the study region. Then this exact time altimeter measurement matches with the in-situ half an hour measurement whichever is close or less than 15 min was considered otherwise rejected for example say the exact altimeter measurement is at 08:17 hrs then the measurement in buoy at 8:30 so the difference between altimeter exact passing time and buoy measurement falls within 15 minutes of time interval for both passes i.e. temporal window of ( 0 - 15 minutes) considered. The spatial window varies for the two tracks considered for the study for the track 155, it is about $50 \mathrm{~km}$ and for the track 116 it was about $18 \mathrm{~km}$ away from the coast.

\section{Results}

The standard altimetry data is restricted to about $50 \mathrm{~km}$ away from the coast by the land mask of the on-board radiometer until recent past. But along-track altimeter footprint size is less than 15 $\mathrm{km}$, depending on the wave height (Madsen, Høyer and Tscherning, 2007). Recent studies suggest that the valuable information can be retrieved in the coastal zone of $0-50 \mathrm{~km}$ by performing more screening on high resolution (raw) along track altimeter data. In the present study, the Jason-2 PISTACH data consists of along track high resolution data products with sampling rate of $20 \mathrm{~Hz}$ were utilized for the study. This PISTACH along track data set contains physical information as close as $5 \mathrm{~km}$ away from the coast along with high frequency noise (Labroue, 2009). Caballero., et al. [31] successfully retrieved the altimeter wave data up to 8-9 $\mathrm{km}$ to the coast by using COASTALT wave data. Acharyulu and Prasad (2014) showed that the valid data available up to 9 and $6 \mathrm{~km}$ away from the coast for the same tracks 116 and 155 respectively. The same Jason-2 ground tracks were chosen for the study. In order to study the PISTACH data in the coastal zones, first the SWH data validity needs to be checked.

\section{SWH data validity proximity to the coast}

An attempt has made to check the data validity with in the 0 - 50 $\mathrm{km}$ coastal strip for the selected tracks by applying the PISTACH processing flag for re-trackers and by restricting the data between $0-50 \mathrm{~km}$ and to retain the valid SWH (ku band only) data close to the coast for different re-trackers.

Figure 2 shows the availability of valid SWH data from different re-trackers within the coastal strip of $0-50 \mathrm{~km}$ and shows that valid SWH data can be retrieved around $6-10 \mathrm{~km}$ close to the coast also.

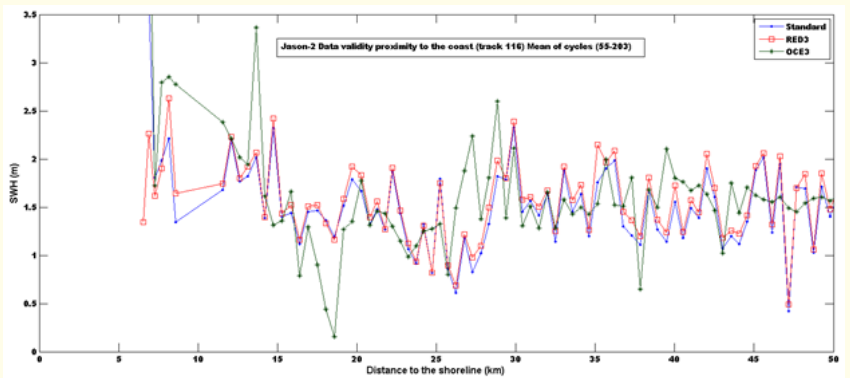

Figure 2: Valid SWH data close to the coast for Standard, RED3 and OCE3 re-trackers for the tracks 155.

But even though the valid altimeter data available up to $\sim 10 \mathrm{~km}$ away from the coast, there is no in situ observations available at this position anywhere along the east coast of India to check the data validity of altimeter at this proximity to the coast. The closest altimeter-buoy distance available is for the track 116 separated by a distance of $18 \mathrm{~km}$. It is also one of the reason for choosing the present study area. 


\section{Closest point analysis}

The concept of closest point analysis was adopted from [26]. It is the point, where the distance between altimeter ground track and the buoy is shortest (or) closest. In this present study region, the altimeter track 155 was passing at a distance of about $50 \mathrm{~km}$ and for track 116 at about $18 \mathrm{~km}$ away from the coastal buoy, which were the closest points from altimeter to the buoy for the tracks 155 and 116 respectively. All the comparisons were carried out at this closest point to obtain best results [3,9,13,15,16,27-35].

\section{Comparison/validation of wave heights of raw data}

Comparison and validation of altimeter SWH can be done by either with buoy measurements or by cross- satellite comparisons [9]. In this study, comparisons were made against buoy data. As mentioned earlier, the PISTACH coastal along track data was obtained after data editing and applying the valid retracking flags to obtain SWH data for all the re-trackers between 10 - $50 \mathrm{~km}$ away from the coast $[12,13,15,21,28,34-38]$. The Jason-2 ground track 155 is an ocean to land ascending track at a distance of about 50 $\mathrm{km}$ away from the buoy while the Jason-2 ground track 116 is a land to ocean descending track at a distance of about $18 \mathrm{~km}$ away from the buoy. The (Figure $3 \mathrm{a}$ and $3 \mathrm{~b}$ ) represent the valid $\mathrm{SWH}$ data selected for the study region between $10-50 \mathrm{~km}$ away from the coast for Standard, OCE3 and RED3 re-trackers for the tracks 155 and 116 respectively.
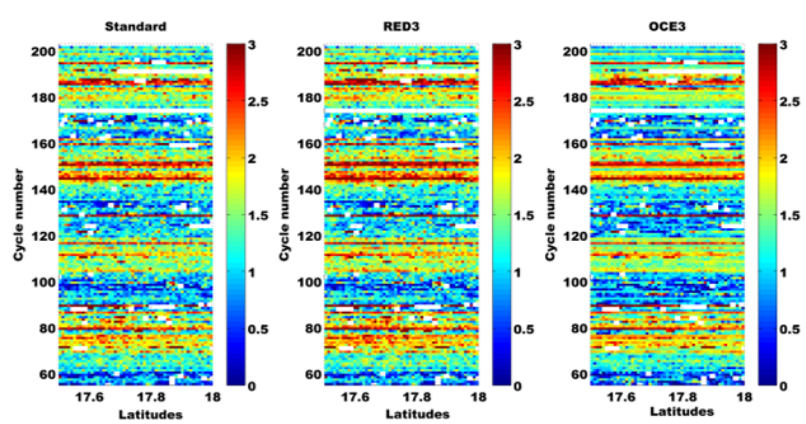

Figure 3a: Valid SWH data between 10 - $50 \mathrm{~km}$ away from the coast for Standard, RED3 and OCE3 re-trackers for the tracks 155.

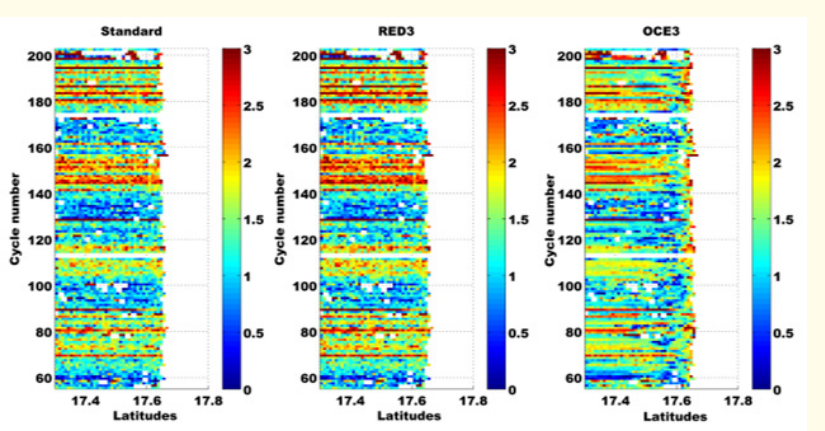

Figure 3b: SWH data between 0 - $50 \mathrm{~km}$ away from the coast for Standard, RED3 and OCE3 re-trackers for the track 116.
All the oceanographic signals such as low wave heights during pre and post monsoon season, increased strip of wave heights during monsoon and also picked up the low pressure systems such as depressions and cyclones as narrow strip of high wave heights were well reproduced in a single year observed in the Jason-2 PISTACH products. As the study period covers from January-2010 to September 2013 for a period of about three years and nine months in duration, it also reveals a lot of valuable information about SWH variability from season to season, year to year and during cyclones. It was also observed that RED3 re-tracker is closely following the standard one and shows a little high spatial variability. In order to make comparisons with the buoy, collocation criteria was followed with the closest point analysis. The number of collocated points available for the Jason-2 ground tracks 155 and 116 are 107 and 111 respectively. Validity does not imply accuracy and therefore the number of valid points does not correspond to the total number of "correct" estimates; nevertheless the outlier detection is applied to exclude extreme values. Since in Jason missions the outlier detection can be extended to SWH [16]. So, the outliers were detected and eliminated as suggested by N Picot., et al [39]. The initial time series comparison plots of SWH for Jason-2 ground track 155 and 116 for each individual re-tracker along with buoy data were presented in figure 4.
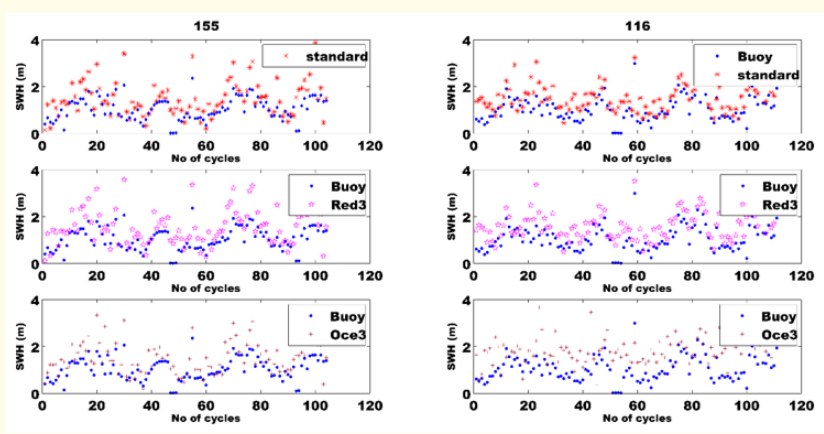

Figure 4: Time series comparison plots of SWH for Jason-2 ground track 155 and 116 for each individual re-tracker with buoy data.

The dominance of seasonal signals were well represented as a wave like pattern was clearly observed in both the tracks, increased part indicating the monsoon and decreased part during pre and post monsoon. In addition to these, some outliers still exist. The presence of outliers in the altimeter data were either due to lowpressure systems, land contamination, etc. [9,10,13,28,33,40-43]. Also this time series comparison plots shows that all the oceanographic signals captured by altimeter at $50 \mathrm{~km}$ for track 155 and $18 \mathrm{~km}$ away from the coast for track 116 were also depicted in the coastal buoy data. The scatter plots for the Jason-2 ground tracks 155 and 116 along with basic statistics presented in figure 5 show that there is an acceptable agreement between altimeter and buoy collocated pairs of standard OCE3 and RED3 re-trackers. 

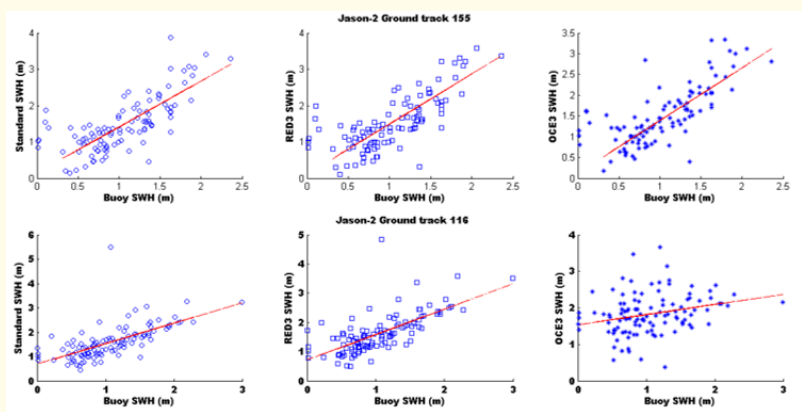

Figure 5: Scatter plots of the Jason-2 ground tracks 155 and 116 for standard, OCE3 and RED3 re-trackers.

It is clear from the figure that for the track 155, the OCE3 retracker seems to less scattered than RED3 and standard. Similarly, for the track 116, RED3 is less scattered than the OCE3 and standard one. The OCE3 re-tracker shows least scattered (less deviation) during all the peaks i.e. for the extreme event cases like cyclones [44]. The commonly reported statistics required for the comparison and validation of the altimeter data with buoy were presented for both the tracks in the table $1 \mathrm{a}$ and $1 \mathrm{~b}$.

For the track 155, the Pearson's correlation coefficient (r) for all the re-trackers were in moderately acceptable range of 0.65 0.75 . For the track 155 OCE3 retracker shows the highest $r$ value of 0.71 while the least was 0.66 for the standard product. The root mean square error (RMSE) used by many investigators (Queffeulou, 2004; Sabique., et al. 2013), [21,45-47], was used to explain the error in the datasets which was also used here in the range of 0.45 - 0.6, which looks like acceptable. The OCE3 re-tracker shows the lowest and RED3 shows the highest RMSE values of 0.47 and 0.59 respectively. The mean bias of different re-trackers computed for the track 155 were in the range of 0.4 to 0.50 while the minimum of 0.4 was for OCE3 and maximum of 0.50 for RED3 re-trackers. The OCE3 re- tracker shows a good matching with buoy data than other re-trackers for the track 155 at a distance of $50 \mathrm{~km}$ away from the coast.

\begin{tabular}{|c|c|c|c|c|c|c|c|c|}
\hline \multicolumn{5}{|l|}{ (a) } & \multicolumn{4}{|l|}{ (b) } \\
\hline Re-tracker & $\begin{array}{l}\text { Collocated } \\
\text { Points }\end{array}$ & RMSE (m) & $\begin{array}{l}\text { Bias (Alt- } \\
\text { Buoy) (m) }\end{array}$ & $\mathbf{r}$ & $\begin{array}{l}\text { Collocated } \\
\text { Points }\end{array}$ & $\begin{array}{l}\text { RMSE } \\
\text { (m) }\end{array}$ & $\begin{array}{c}\text { Bias (Alt-Buoy) } \\
\text { (m) }\end{array}$ & $\mathbf{r}$ \\
\hline Standard & 104 & 0.71 & 0.484 & 0.60 & 111 & 0.53 & 0.52 & 0.8 \\
\hline RED 3 & 104 & 0.73 & 0.572 & 0.63 & 111 & 0.50 & 0.58 & 0.82 \\
\hline OCE 3 & 104 & 0.43 & 0.462 & 0.77 & 111 & 0.54 & 0.78 & 0.50 \\
\hline
\end{tabular}

Table 1: Statistics of comparison and validation of PISTACH raw products for the (a) track 155 (b) track 116.

Similarly, for the track 116, the r values for different re-trackers were in the range of $0.26-0.68$, while the highest 0.68 for RED3 and the poorest for OCE3 re-trackers with the coastal buoy. The RMSE values were in the range of 0.54 to 0.50 , the highest of 0.54 for OCE3 and lowest of 0.50 for RED3. The mean bias values were in the range of 0.52 to 0.77 , the highest and lowest values of 0.77 and 0.52 for OCE3 and RED3 re-trackers respectively. Here, the RED3 re-tracker shows a better matching than the others for the track 116 at a distance of $18 \mathrm{~km}$ away from the coast.

An overall statistics for both the tracks suggests that at $50 \mathrm{~km}$ distance OCE3 and at $18 \mathrm{~km}$ distance from the coast RED3 show better matching with buoy measurements. The reason for these high RMSE values are due to high frequency $20 \mathrm{~Hz}$ data. Also, here the reason for this high bias values are attributed to two factors, one is due to raw high frequency $20 \mathrm{~Hz}$ data which contains noise and also due to the presence of buoy close to the coast in shallow water. It was observed from the statistics of both the tracks that the bias values for track 155 were less as compared to the track 116. The reason for this behavior was not only due to open and coastal ocean conditions but due to land contamination and may be due to other processes in the altimeter footprint of the track 116 $[16,28,48]$. Because here the location of the buoy at about $1.3 \mathrm{~km}$ away from the coast indicates that it is coastally located and the closest altimeter -buoy distance for the track 116 was at least 18 $\mathrm{km}$ away from the coast indicates that the wave information obtained was still a deep water wave. M Cancet., et al. [28] also suggested that it would be interesting to evaluate the biases from different re-trackers dedicated to coastal areas. It was observed that the excellent behavior of OCE3 was for open ocean and during low pressure systems and RED3 for coastal ocean and low-mid range values of SWH. These results show the potential use of altimeter data in the coastal regions on the east coast of India. 


\section{Comparison/validation of wave heights after processing}

The PISTACH raw $20 \mathrm{~Hz}$ along track data contains high frequency noise and in order to remove this high frequency noise, a low pass and spatial filtering was necessary but correlation scales may vary (Ray and Beckley 2012; Labroue 2009; Picot., et al. 2003; Queffeulou 2004; Cancet., et al. 2013; Vignudelli., et al. 2005; Bouffard., et al. 2010). Here, Lanczos (low pass) filter applied along with a spatial filter at different spatial points of 5,9,11,21,41 on newly developed RED3 and OCE3 retracking data of $20 \mathrm{~Hz}$ PISTACH products [31]. The processing enables us to improve valid and reliable estimates of wave heights in proximity of the coast.

\section{Track 155}

The time series comparison of RED3 and OCE3 re-trackers with different spatial filtering for the track 155 were presented in figure 6.
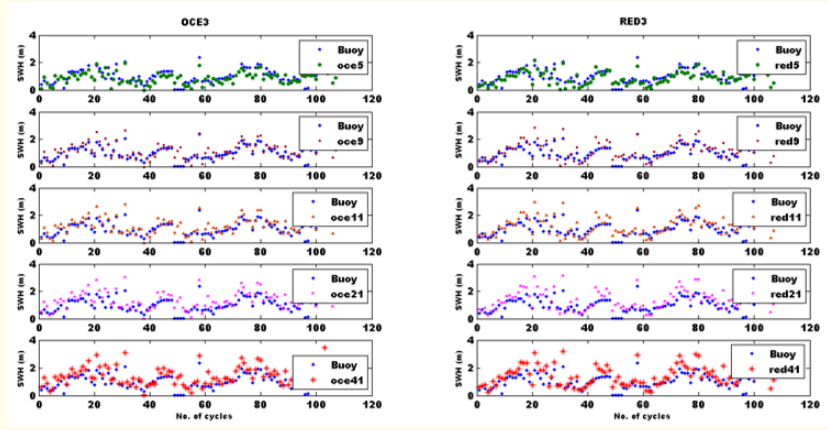

Figure 6: Time series comparison of RED3 and OCE3 re-trackers with different spatial filtering for the track 155.

It was observed that in both the re-trackers, the deviation between altimeter and buoy datasets was least for low spatial filtered data and high spatial filter data shows higher deviation with buoy measurements. It is obvious from the figure that large spatial variability of wave heights were observed in less spatial filtered data and low variability of wave heights in high spatial filtered data. The seasonal signal was observed in all the spatial filtered data of both the re-trackers. It was also observed that the noise was significantly reducing from least spatial filtered data (5 points) to high spatial filtered data (41 points). In RED3 re-tracker, the 41 point filter data shows good matching with the buoy data for low to moderate wave height range but showing large deviation for higher values of wave height where as in OCE3 re-tracker the 41 point filter shows excellent agreement with buoy data and comparatively lower bias values for higher wave heights. The scatter plots of different spatial filters for RED3 as well as OCE3 re-trackers with in-situ data were presented in figure 7.

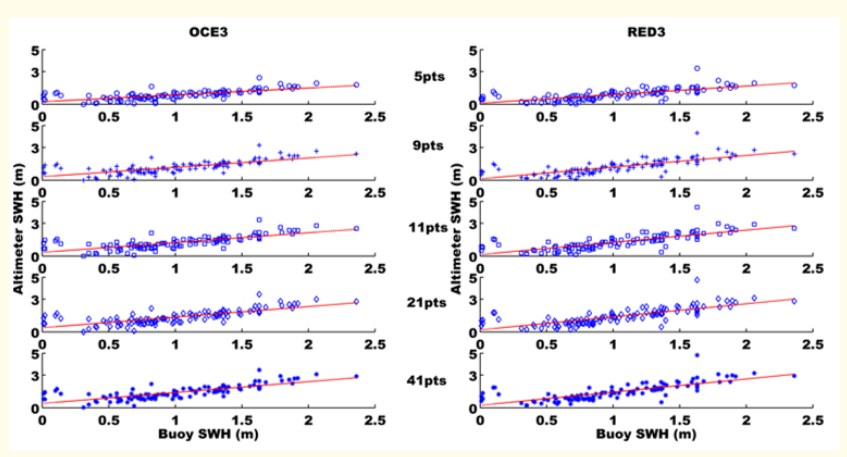

Figure 7: Scatter plots of different spatial filters for RED3 as well as OCE3 re-trackers with In-situ data for the track 155.

The comparison statistics of RED3 and OCE3 with different spatial filters after processing for the track 155 were presented in the table 2 and 3.

\begin{tabular}{|l|c|c|c|}
\hline Spatial filter & RMSE (m) & Bias (Alt-Buoy) (m) & r \\
\hline 5pts & 0.31 & -0.1435 & 0.7 \\
\hline 9pts & 0.399 & 0.173 & 0.72 \\
\hline 11pts & 0.41 & 0.23 & 0.72 \\
\hline 21pts & 0.42 & 0.35 & 0.74 \\
\hline 41pts & 0.41 & 0.40 & 0.76 \\
\hline
\end{tabular}

Table 2: Comparison statistics of OCE3 with different spatial filters after processing for the track 155.

\begin{tabular}{|l|c|c|c|}
\hline Spatial filter & RMSE (m) & Bias (Alt-Buoy) (m) & r \\
\hline 5pts & 0.36 & -0.11 & 0.73 \\
\hline 9pts & 0.467 & 0.20 & 0.75 \\
\hline $11 p t s$ & 0.48 & 0.26 & 0.756 \\
\hline $21 p t s$ & 0.50 & 0.38 & 0.76 \\
\hline $41 p t s$ & 0.50 & 0.44 & 0.763 \\
\hline
\end{tabular}

Table 3: Comparison statistics of RED3 with different spatial filters after processing for the track 155.

The $r$ values for the RED3 re-tracker lies in the range of 0.73 0.76 with the highest value of 0.76 for 41 point and lowest of 0.73 for 5 point filters. The $r$ value of the RED3 re-tracker was significantly improved from 0.68 to a maximum of 0.76 after processing. But it increases slightly from 0.73 for 5 point to 0.76 for 41 point filter. The RMSE values for the RED3 re-tracker were in the range of 0.36 to 0.50 , the highest of 0.50 for 41 point and lowest of 0.36 for 5 point filters. After applying filters, the RMSE was improved from 0.59 to 0.50 in the worst case for 41 point filter. But it increas- 
es from 0.36 for 5 point to 0.50 for 41 point filter. The mean bias values were in the range of -0.11 to 0.44 , the highest and lowest values of 0.44 and -0.11 for 41 and 5 point filters respectively. The mean bias values were significantly reduced from 0.50 (before filter) to 0.44 maximum for 41 point filter (after filtering). It also shows a large variation from negative bias of -0.11 for 5 point filter to a maximum positive bias of 0.44 for 41 point filter. This shows that the RED3 re-tracker performance was greatly improved after applying filters [24].

The r values for OCE3 re-tracker were in the range of 0.71-0.76, while the highest of 0.76 for 41 and the lowest for 5 point filters. The improvement in $r$ value for the OCE3 re-tracker was from 0.71 before processing to a maximum of 0.76 after processing. But it increases from 0.71 for 5 point to 0.76 for 41 point filter. The RMSE values were in the range of 0.31 to 0.41 , the large value of 0.41 for 41 and small value of 0.31 for 5 point filters. After applying filters, the RMSE was improved from 0.47 to 0.41 in the worst case for 41point filter. But it increases from 0.31 for 5 point to 0.41 for 41 point filter. The mean bias values were in the range of -0.14 to 0.40 , the highest and lowest values of 0.40 and -0.14 for 41 and 5 point filters respectively. The mean bias values were significantly reduced from 0.50 (before filter) to 0.44 maximum for 41 point filter (after filtering). It also shows a large variation from negative bias of -0.11 for 5 point filter to a maximum positive bias of 0.44 for 41 point filter. The overall statistics for OCE3 suggests that 41 point filter shows good correlation scales with an acceptable error. This shows that the OCE3 re-tracker performs well for this track 155 and at a distance of $50 \mathrm{~km}$ away from the coast was significantly improved after applying filters.

After applying filters, different correlation scales with buoy data were observed for different spatial filtered data of both the re-trackers. The correlation scales were significantly improved for both the re-trackers. RED3 re-tracker performance was observed to be much improved after processing. But OCE3 re-tracker shows an overall good performance with buoy observations.

\section{Track 116}

In this track 116 also the dominance of seasonal signal was observed in all the spatial filtered data of both the re-trackers $[5,13]$. The comparison and validation of this track is of more concern as compared to track 155 as the track 116 was passing comparatively closer and more importantly in the strip of the coastal zone. But it is a land to ocean descending track [3]. The data validity was around $10 \mathrm{~km}$ close to the coast. The time series comparison of RED3 and OCE3 re-trackers with different spatial filtering for the track 116 were presented in figure 8.
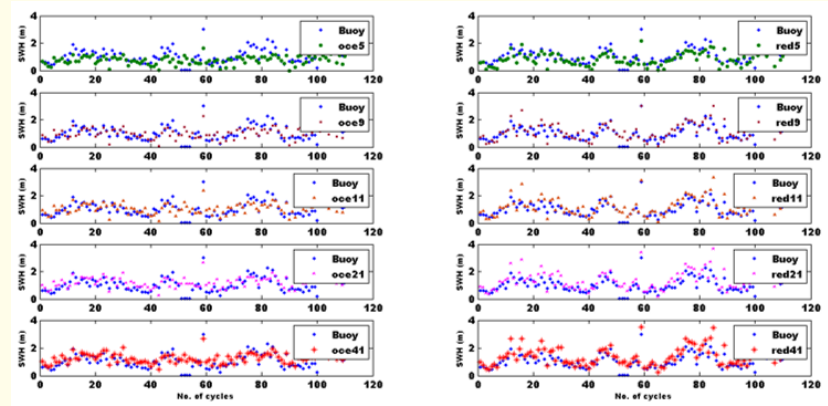

Figure 8: Time series comparison of RED3 and OCE3 re-trackers with different spatial filtering for the track 116.

In RED3 re-tracker, the 41 point filter data shows excellent matching with the buoy data for low to moderate wave height range but showing large deviation for higher values of wave height where as in OCE3 re-tracker the 41 point filter shows moderate to low agreement with buoy data and comparatively less deviation for higher wave heights. The scatter plots of different spatial filters for RED3 as well as OCE3 re-trackers with in-situ data were presented in figure 9.
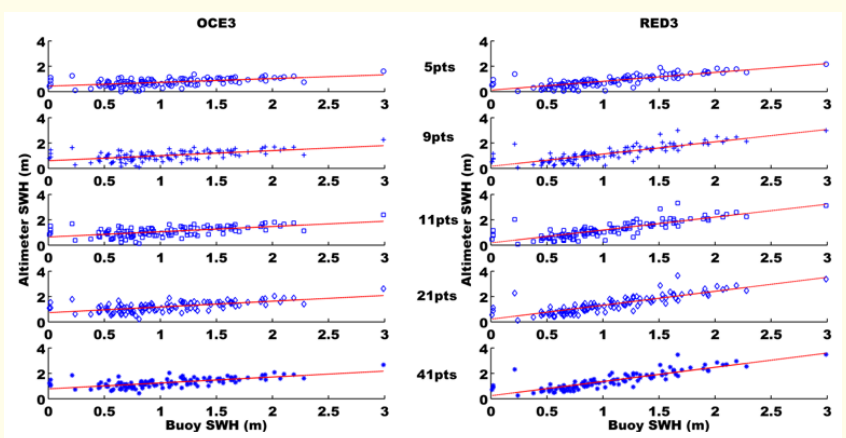

Figure 9: Scatter plots of different spatial filters for RED3 and OCE3 re-trackers against buoy data for the track 116.

It can clearly observed from the figure that in this particular track 116, the OCE3 is more scattered than RED3. The comparison statistics of RED3 and OCE3 with different spatial filters after processing for the track 116 were presented in the table 4 and 5 . 


\begin{tabular}{|l|c|c|c|}
\hline Spatial filter & RMSE (m) & Bias (Alt-Buoy) (m) & r \\
\hline 5pts & 0.265 & -0.30 & 0.51 \\
\hline 9pts & 0.324 & -0.030 & 0.544 \\
\hline 11pts & 0.325 & 0.02 & 0.558 \\
\hline 21pts & 0.306 & 0.149 & 0.616 \\
\hline 41pts & 0.280 & 0.21 & 0.662 \\
\hline
\end{tabular}

Table 4: Comparison statistics of OCE3 with different spatial filters after processing for the track 116.

\begin{tabular}{|l|c|c|c|}
\hline Spatial filter & RMSE (m) & Bias (Alt-Buoy) (m) & r \\
\hline 5pts & 0.282 & -0.201 & 0.793 \\
\hline 9pts & 0.368 & 0.126 & 0.812 \\
\hline 11pts & 0.379 & 0.193 & 0.818 \\
\hline 21pts & 0.376 & 0.319 & 0.836 \\
\hline 41pts & 0.354 & 0.365 & 0.86 \\
\hline
\end{tabular}

Table 5: Comparison statistics of RED3 with different spatial filters after processing for the track 116.

For this track also on applying filters, different correlation scales were observed for different spatial filtered data of both the re-trackers. Filtering improves the correlation scales significantly for both the re-trackers. The maximum improvement was observed in RED3 re-tracker. The $r$ value for the RED3 re-tracker lies in the range of $0.79-0.86$ with the highest value of 0.86 for 41 point and lowest of 0.79 for 5 point filters. The RMSE values for the RED3 re-tracker were in the range of 0.28 to 0.35 , the highest of 0.35 for 41 points and lowest of 0.28 for 5 points. The mean bias values were in the range of -0.20 to 0.36 , the highest and lowest values of 0.36 and -0.20 for 41 and 5 point filters respectively. The $r$ values for OCE3 re-tracker were in the range of $0.51-0.66$, while the highest of 0.66 for 41 and the lowest of 0.51 for 5 point filters. The RMSE values were in the range of 0.26 to 0.28 , the large value of 0.28 for 41 and small value of 0.26 for 5 point filters. The mean bias values were in the range of -0.30 to 0.21 , the highest and lowest values of -0.30 and 0.21 for 41 and 5 point filters respectively. It was observed that the 41 point filter data shows good correlation with the in-situ measurement than the other spatial filters. This 41 point filter also picks up all the signals that are captured in $20 \mathrm{~Hz}$ data. The performance of the RED3 re-tracker was very much improved after processing the data, a similar result of improvement in RED3 re-tracker with standard product (MLE4) after calibration was observed by S Labroue., et al [24]. Here, at this position of $18 \mathrm{~km}$ away from the coast, RED3 re-tracker was observed to performs well with in-situ data and show more promising results close to the coast. It was also observed that OCE3 re-tracker captures all the signals especially during severe weather conditions with less error that were reflected in the buoy data. An improvement in wave information at different frequencies or spatial scales and thereby extending the wave information up to 8 - $9 \mathrm{~km}$ were earlier observed by I Caballero., et al [31]. Here, it was observed that 41 point filter of RED3 and OCE3 re-tracker data in both the tracks 155 and 116 shows better statistics but due to lack of wave information at intermediate depths or at $5-20 \mathrm{~km}$ coastal strip has restricted this study to $18 \mathrm{~km}$ away from the coast only. Here, It is also important to observe that in both the re-trackers the wave data still contain some erroneous data outliers especially in extremes values (both very high and very low wave heights) of SWH which was also observed by P Challenor and P Cotton [49] that the difficulty in validation of the altimeter data at extreme values as little data available to work for high sea states which are a rare cases and the difficulty in measuring wave heights lower than about $0.5 \mathrm{~m}$ in all measurements by altimeter [49]. Also, here as mentioned earlier, the comparison and validation was made with a coastal buoy at a distance of $1.3 \mathrm{~km}$ away from the coast to Jason-2 ground tracks 155 and 116 at a distance of 50 and $18 \mathrm{~km}$ respectively. It means the concept of open and coastal conditions apply here otherwise the results would be much more improved. Therefore, the scope for improvement of paper lies in comparison of these altimeter - buoy data sets at the same location in the coastal regions(as close as possible) and also to check with other newly developed re-trackers (like ALES etc.,) and at different frequencies. But still the results were quite encouraging and promising to obtain reliable wave estimates in the limited areas on the east coast of India. This shows the potential use of both the re-trackers in understanding the wave climate in the coastal strip on the east coast of India.

\section{Conclusions}

The present study was intend to observed wave information as close as possible to the coast and to validate newly developed different re-trackers available in the PISTACH coastal products of the Jason-2 data. It was observed from the study that Jason-2 data is valid as close as $10 \mathrm{~km}$ away from the coast. The coastal region off Visakhapatnam on East coast of India was influenced by North East monsoon, pre-monsoon, South west monsoon and post monsoon periods [50] which were primary oceanographic signals clearly picked up by altimeter in all the measurements. In this study differ- 
ent re-trackers from the Jason-2 PISTACH coastal products were used to observe the performance of the re-trackers for different conditions. Of the new three additional re-trackers available with the PISTACH coastal products (Standard, OCE3 and RED3 re-trackers) shows the availability of valid data around $\sim 10 \mathrm{~km}$ close to the coast also. The new re-trackers RED3 and OCE3 which were developed during Jason-2 PISTACH project for the study of coastal regions shows better performance. Both the re-trackers in both the tracks capture all the oceanographic information that are observed from buoy data. It was observed that RED3 re-tracker performs well in the coastal region and provides optimum results.

The comparison of the track 155 with the coastal buoy was merely to observe for signal only because it is too far (about 50 $\mathrm{km}$ ) away from the coastal buoy. The comparison and validation results suggest that there is a significant improvement in significant wave height (SWH) data in terms of noise and accuracy after processing. Spatial and low pass filtering produces different statistics with the observed data. This data will be useful to study the spatial variability and better understanding of coastal dynamics in these limited areas.

The performance of the RED3 re-tracker was very much improved after processing the data. It was observed that RED3 retracker shows better matching with the moderate wave height ranges and better results proximity to the coast where as OCE3 retracker captures all the signals especially during severe weather conditions with less error and better observations at intermediate and open waters. It is also important to observe that in both the re-trackers the wave data still contain some erroneous data outliers especially in extremes values. This suggests that there is a need to improve better detection of outliers, which were present even after processing. Also there is a need to enhance or modify the collocation criteria for coastal regions otherwise the wave which was observed by the altimeter and the buoy will not be the same. This study shows that the comparison of altimetry data with the coastal buoy data extends the valid altimeter data from $50 \mathrm{~km}$ to $18 \mathrm{~km}$ away from the coast.

The results were quite encouraging to use the altimetry data in the coastal regions on the east coast of India in understanding the wave climate in the coastal zone on the east coast of India.

\section{Acknowledgements}

The authors express our sincere acknowledge Space Applications Center (ISRO) for providing financial support during this work. We express our sincere gratitude to INCOIS and AVISO for providing the buoy and altimeter data and their constant support. We would like to thank Prof. B.S.R Reddy, Raj Kumar and RM Gairola for their support and encouragement.

\section{Bibliography}

1. P Janssen. "ECMWF wave modeling and satellite altimeter wave data”. Elsevier 63 (2000).

2. E Walsh. "Extraction of ocean wave height and dominant wavelength from Geos 3 altimeter data". Journal of Geophysical Research: Solid Earth 84.B8 (1979): 4003.

3. H E Krogstad and S F Barstow. "Satellite wave measurements for coastal engineering applications". Coastal Engineering 37.3 (1999): 283-307.

4. P Queffeulou. "Quality of long term satellite wind and wave measurements". In ERS-Envisat Symposium (2000).

5. P Challenor., et al. "Satellite altimetry: A revolution in understanding the wave climate". in Proceedings of the Symposium on 15 Years of Progress in Radar Altimetry (2006): 13-18.

6. P G Challenor and P D Cotton. "The joint calibration of altimeter and in situ wave heights". Adv. Appl. Mar. Climatol. Dyn. part WMO Guid. to Appl. Mar. Climatol. WMO/TD. 1081 (2002).

7. PA E M Janssen., et al. "Error Estimation of Buoy, Satellite, and Model Wave Height Data". Journal of Atmospheric and Oceanic Technology 24.9 (2007): 1665-1677.

8. ED Kumar., et al. "Wind-Wave Characteristics and Climate Variability in the Indian Ocean Region Using Altimeter Data". Marine Geodesy 36.3 (2013): 303-318.

9. P Queffeulou. "Long-Term Validation of Wave Height Measurements from Altimeters". Marine Geodesy 27.3-4 (2004): 495510.

10. B G Reguero., et al. "A Global Ocean Wave (GOW) calibrated reanalysis from 1948 onwards". Coastal Engineering 65 (2012): 38-55.

11. I R Young. "An intercomparison of GEOSAT, TOPEX and ERS1 measurements of wind speed and wave height". Ocean Engineering 26.1 (1998): 67-81.

12. P Cipollini., et al. "Coastal Altimetry Data Handbook" (2013).

13. S Vignudelli., et al. "Improved satellite altimetry in coastal systems: Case study of the Corsica Channel (Mediterranean Sea)". Geophysical Research Letter 32.7 (2005): 1-5. 
14. J Gómez-Enri., et al. "COASTALT: improving radar altimetry products in the oceanic coastal area". in SPIE Remote Sensing (2008): 71050J-71050J.

15. F Mercier., et al. "Coastal and Hydrology Altimetry product (PISTACH) handbook". Cent. Natl. d'\{É\}tudes Spat. (CNES), Paris, Fr., (2010).

16. M Passaro., et al. "ALES: A multi-mission adaptive subwaveform retracker for coastal and open ocean altimetry". Remote Sensing of Environment 145 (2014): 173-189.

17. G Valladeau., et al. "Using SARAL/AltiKa to Improve Ka-band Altimeter Measurements for Coastal Zones, Hydrology and Ice: The PEACHI Prototype". Marine Geodesy (2015).

18. P Cipollini., et al. "The role of altimetry in coastal observing systems". Proceedings of Ocean 9 (2010): 181-191.

19. A Sarkar., et al. "Inter-comparison of model-predicted wave heights with satellite altimeter measurements in the north Indian Ocean". Ocean Engineering 24.9 (1997): 879-885.

20. L Sabique., et al. "Comparison of Grid Averaged Altimeter and Buoy Significant Wave Heights in the Northern Indian Ocean". Marine Geodesy 36.1 (2013): 72-85.

21. P R Shanas., et al. "Comparison of gridded multi-mission and along-track mono-mission satellite altimetry wave heights with in situ near-shore buoy data". Ocean Engineering 83 (2014): 24-35.

22. F J Ocampo-Torres. "Significant wave height from ERS altimeter for water wave studies in coastal regions". European Space Agency (ESA) (1997): 1239-1242.

23. V R Rao., et al. "Near shore circulation and sediment transport pattern along Gangavaram - Visakhapatnam coast, east coast of India". International Journal of Earth Sciences and Engineering 2014 (2014): 5-7.

24. S Labroue., et al. "Level 3 PISTACH Products for Coastal Studies". In $5^{\text {th }}$ coastal altimetry workshop (2011): 1-23.

25. F Monaldo. "Expected differences between buoy and radar altimeter estimates of wind speed and significant wave height and their implications on buoy-altimeter comparisons". Journal of Geophysical Research 93 (1988): 2285.

26. M Passaro., et al. "Validation of significant wave height from improved satellite altimetry in the German bight". IEEE Transactions on Geoscience and Remote Sensing 53.4 (2015): 21462156.
27. L Cavaleri. "The wind and wave atlas of the Mediterranean Sea - the calibration phase". Advances in Geosciences 2 (2005): 255257.

28. M Cancet., et al. "Regional in situ validation of satellite altimeters: Calibration and cross-calibration results at the Corsican sites". Advances in Space Research 51.8 (2013): 1400-1417.

29. Y Cheng., et al. "Integrating Non-Tidal Sea Level data from altimetry and tide gauges for coastal sea level prediction". Advances in Space Research 50.8 (2012): 1099-1106.

30. Y Kushnir., et al. "The Recent Increase in North Atlantic Wave Heights*”. Jornal of Climate 10.8 (1997): 2107-2113.

31. I Caballero., et al. "Advances in the validation of coastal altimetry full rate wave data (COASTALT PROJECT )". In $5^{\text {th }}$ Coastal Altimetry Workshop (2011).

32. X Feng., et al. "Changes in significant and maximum wave heights in the Norwegian Sea". Global and Planetary Change 113 (2014): 68-76.

33. R H Stewart., et al. "Statistics of geostrophic turbulence in the southern ocean from satellite altimetry and numerical models". Physica D: Nonlinear Phenomena 98.2-4 (1996): 599-613.

34. F Durand., et al. "Estimating boundary currents from satellite altimetry: A case study for the east coast of India". Journal of Oceanography 64.6 (2008): 831-845.

35. R D Ray and B D Beckley. "Calibration of Ocean Wave Measurements by the TOPEX, Jason-1, and Jason-2 Satellites". Marine Geodesy 35.1 (2012): 238-257.

36. L Roblou., et al. "X-track, a new processing tool for altimetry in coastal oceans”. IEEE Int. Geosci. Remote Sens. Symp., (2007).

37. F Durand., et al. "Spatiotemporal structure of the East India Coastal Current from satellite altimetry". Journal of Geophysical Research 114.C2 (2009): C02013.

38. M Cancet., et al. "CTOH regional altimetry products: examples of applications". Proceedings of Ocean 9.1 (2009): 306.

39. N Picot., et al. "\{PODAAC $\}$ User Handbook". $\{$ IGDR and GDR Jason Products (2003).

40. S Abdalla., et al. "Jason-2 OGDR Wind and Wave Products: Monitoring, Validation and Assimilation". Marine Geodesy 33.1 (2010): 239-255.

41. F G Lemoine., et al. "Towards development of a consistent orbit series for TOPEX, Jason-1, and Jason-2". Advances in Space Research 46.12 (2010): 1513-1540. 
42. T Niedzielski and $\mathrm{W}$ Kosek. "Minimum time span of TOPEX/ Poseidon, Jason-1 and Jason-2 global altimeter data to detect a significant trend and acceleration in sea level change". Advances in Space Research 47.7 (2011): 1248-1255.

43. J R E Lutjeharms., et al. "Agulhas cyclones. Deep-Sea Research Part II". Topical Studies in Oceanography 50.1 (2003): 13-34.

44. K Prasad., et al. "Application of Altimetry in assessing extreme winds and waves during cyclone period - a case study of LAILA cyclone". In Pan Ocean Remote Sensing Conference (PORSEC) (2012).

45. M Hemer., et al. "Waves and climate change on the Australian coast". Journal of Coastal Research 2007.50 (2007): 432-437.

46. D Cromwell and C. Gommenginger. "Developing global longterm altimeter datasets and climatologies of ocean wave measurements" (2009): 14-17.

47. B G Reguero., et al. "A Global Ocean Wave (GOW) calibrated reanalysis from 1948 onwards". Coastal Engineering 65 (2012): 38-55.

48. D B Chelton., et al. "Chapter 1 Satellite Altimetry". In International Geophysics. F. Lee-Lueng and C. Anny, Eds. Academic Press (2001): 1-ii.

49. P Challenor and P Cotton. "The joint calibration of altimeter and in situ wave heights". Doc. WMO/TD-1081, JCOMM Tech. Rep (2002): 139-148.

50. S D Attri and A Tyagi. "Government of India Ministry of Earth Sciences CLIMATE PROFILE OF INDIA Contribution to the Indian Network of Climate Change Assessment S D Attri and Ajit Tyagi”. New Delhi (2010).

\section{Assets from publication with us}

- Prompt Acknowledgement after receiving the article

- Thorough Double blinded peer review

- Rapid Publication

- Issue of Publication Certificate

- High visibility of your Published work

Website: https://www.actascientific.com/

Submit Article: https://www.actascientific.com/submission.php

Email us: editor@actascientific.com

Contact us: +919182824667 